\title{
Beneficiamento pós-colheita de lima ácida 'Tahiti’ afeta sua qualidade e conservação
}

\author{
Postharvest packing process of 'Tahiti' acid lime affects their quality and conservation
}

\begin{abstract}
Meire Menezes Bassan ${ }^{I}$ Francisco de Assis Alves Mourão Filho ${ }^{I{ }^{*}}$ Renan Fernandes Alves ${ }^{\text {III }}$ Débora Fernandes Bezerra ${ }^{\text {II }}$ Hilton Thadeu Zarate Couto ${ }^{\text {IV }}$ Angelo Pedro Jacomino ${ }^{\text {II }}$
\end{abstract}

RESUMO

O objetivo deste trabalho foi determinar os efeitos das etapas de beneficiamento pós-colheita de lima ácida 'Tahiti' na sua qualidade e conservação. Foram utilizados frutos colhidos por torção, em estádio de maturação fisiológica e beneficiados de acordo com o procedimento para frutos de exportação. Foram estabelecidos cinco pontos de coleta de frutos ao longo do processo de beneficiamento, os quais correspondem aos tratamentos estudados: "Campo"- coleta diretamente na planta; "Recepção"na área de recepção da unidade de beneficiamento; "Repouso"após a primeira etapa do beneficiamento; "Beneficiamento completo"- após o beneficiamento completo; e "Centro de comercialização"- na recepção do centro de comercialização. Foram conduzidas análises físicas e químicas durante 20 dias de armazenamento a $22 \pm 2{ }^{\circ} \mathrm{C}$ e $70 \pm 5 \%$ de UR. Os frutos que passaram pelo processo de beneficiamento completo e os que foram coletados no centro de comercialização apresentaram maior perda de massa fresca, maior incidência de oleocelose, menor porcentagem de frutos em condição de comercialização ao final do período de armazenamento, escurecimento da polpa e maior degradação de ácido ascórbico. A qualidade e conservação dos frutos de lima ácida 'Tahiti' foram prejudicadas pela movimentação, manipulação e injúrias mecânicas que ocorrem durante as etapas de beneficiamento pós-colheita.

Palavras-chave: Citrus latifolia, injúria mecânica, unidade de beneficiamento, perdas pós-colheita.

\section{ABSTRACT}

This study aimed to determine the effects of postharvest packing line stages of 'Tahiti' acid lime on their quality and conservation. Fruits were harvested by twisting in physiological maturation stage and packed according to the procedure for export fruits. Five sampling points were set throughout the packing line, which correspond to the treatments studied: "Field"- sampling directly in the plant; "Reception"- collection in the reception area of the packinghouse; "Rest"- collection after the first stage of the packing process; "Complete packing"- collection at the end of the packing process; "Marketing center" and collects at the reception area of the marketing center. Physical and chemical analyzes were conducted for 20 days of storage at $22 \pm 2^{\circ} \mathrm{C}$ and $70 \pm 5 \%$ RH. Fruits that have gone through the complete packing process and those collected in the marketing center had higher fresh mass loss, higher incidence of oleocellosis, lower percentage of fruit on condition of marketing at the end of the storage period, pulp browning and higher degradation of ascorbic acid. Quality and conservation of 'Tahiti' lime fruits were affected by movement, handling and mechanical injuries that occur during postharvest processing.

Key words: Citrus latifolia, mechanical injury, packing-house, postharvest losses.

\section{INTRODUÇÃO}

Os principais atributos de qualidade exigidos para a lima ácida 'Tahiti', visando obter uma comercialização rentável, tanto no mercado interno como externo, são forma, tamanho, brilho, sabor, valor nutritivo, segurança alimentar, coloração verde e turgescência (GAYET \& SALVO FILHO, 2003). Para garantir a comercialização desta fruta, conforme os padrões de qualidade exigidos pelo

\footnotetext{
IPrograma de Pós-graduação em Fitotecnia, Escola Superior de Agricultura “Luiz de Queiroz" (ESALQ), Universidade de São Paulo (USP), Piracicaba, SP, Brasil.

IIDepartamento de Produção Vegetal, ESALQ, USP, 13418-900 Piracicaba, SP, Brasil. E-mail: francisco.mourao@usp.br. *Autor para correspondência.

IIIPrograma de Pós-graduação em Fitopatologia, ESALQ, USP, Piracicaba, SP, Brasil.

${ }^{\text {IV }}$ Departamento de Ciências Florestais, ESALQ, USP, Piracicaba, SP, Brasil.
} 
mercado consumidor, é realizado um processo de beneficiamento após a colheita, o qual visa ampliar o período de conservação das características de qualidade provenientes do campo.

O beneficiamento da lima ácida 'Tahiti' é iniciado logo após a colheita e é composto pelas seguintes etapas: recepção, lavagem e seleção, aplicação de regulador vegetal (frutos destinados à exportação), repouso de $12 \mathrm{~h}$ em condições ambiente de temperatura e umidade $\left(25 \pm 5^{\circ} \mathrm{C}\right.$ e $60 \pm 5 \%$ de UR), aplicação de cera e fungicida, classificação e embalagem, paletização e resfriamento (frutos destinados à exportação). Apesar da aplicação dos devidos tratamentos pós-colheita durante o processo de beneficiamento, produtores e exportadores de lima ácida 'Tahiti' têm observado redução na qualidade da fruta durante o transporte, armazenamento $\mathrm{e}$ comercialização. Dentre as causas dessas perdas, destacam-se aquelas devidas à ocorrência de injurias mecânicas, as quais podem causar danos irreparáveis aos produtos, reduzindo sua vida útil e provocando uma consequente desvalorização comercial (DURIGAN et al., 2005).

Trabalhos de pesquisa envolvendo a lima ácida 'Tahiti', tangerinas 'Rainha' e 'Montenegrina', abacates 'Fuerte' e 'Hass', e pêssegos 'Aurora-1' têm indicado alterações significativas na qualidade, em especial, no que se refere à coloração da casca, perda de massa e alteração de atributos da qualidade interna desses frutos, quando submetidos a danos físicos (DURIGAN et al., 2005; KASAT et al., 2007; MONTERO et al., 2009; FISCHER et al., 2011; BASSAN et al., 2013). Portanto, o estudo do processo de beneficiamento das limas ácidas 'Tahiti' poderá identificar suas limitações, visando sua otimização.

Este trabalho teve por objetivo determinar os efeitos das etapas de beneficiamento pós-colheita de lima ácida 'Tahiti' na sua qualidade e conservação.

\section{MATERIAL E MÉTODOS}

A colheita dos frutos foi realizada em novembro de 2010, mês de entressafra da fruta no Estado de São Paulo, em pomares comerciais, localizados no município de Itajobi/SP (21 ${ }^{\circ} 19^{\prime} 05^{\prime}$ S, 49 03 ' $16^{\prime \prime}$ O e 453m de altitude) e beneficiados na unidade de beneficiamento (UB) da empresa Itacitrus Agroindústria Exportadora S/A, localizada na mesma cidade. Foram utilizados frutos provenientes de plantas com idade média de 7 anos, do clone Quebra-galho de lima ácida 'Tahiti' (Citrus latifolia Tanaka), enxertados em limoeiro 'Cravo' (Citrus limonia Osbeck), colhidos em estádio de maturação fisiológica de acordo com os padrões de qualidade utilizados para exportação (casca rugosa, de cor verde oliva brilhante, diâmetro da região equatorial entre 47 e $65 \mathrm{~mm}$ ).

As limas ácidas 'Tahiti' foram colhidas por torção (exceção no tratamento controle em que a colheita foi realizada com o auxílio de uma tesoura de colheita), acomodadas em caixas plásticas de colheita (27kg), forradas com espuma (espessura de $1 \mathrm{~cm}$ ) e transportadas até a UB. A sanitização dos frutos foi realizada numa balsa de $4000 \mathrm{~L}$ de capacidade, com dióxido de cloro $\left(0,75 \mathrm{~mL} \mathrm{~L}^{-1}\right)$. Em seguida, os frutos foram selecionados, retirando-se aqueles danificados, fora do padrão de cor e de tamanho. Na etapa seguinte, os frutos foram tratados com o regulador vegetal ácido giberélico (GA) (Pro-Gibb ${ }^{\circledR} 10 \%$ i.a.), na concentração de $100 \mathrm{~g}$ do produto comercial para 100 litros de água, e colocados em repouso por 12 horas em condição ambiente de temperatura e de umidade $\left(25 \pm 5^{\circ} \mathrm{C}\right.$ e $60 \pm 5 \%$ de UR). Em seguida, receberam a aplicação de cera a base de carnaúba (Aruá BR, 18\% de sólidos solúveis) na dose de $1 \mathrm{~kg}$ por tonelada de fruto, com adição do fungicida Magnate 500CE (Imazalil 50\% i.a.) e o sanitizante dióxido de cloro nas doses 200 e $100 \mathrm{~mL}$ do produto comercial por 100 litros de cera, respectivamente. Por último, os frutos foram acondicionados em caixas plásticas de colheita $(27 \mathrm{~kg})$, sendo que apenas os frutos a serem enviados para o centro de comercialização (CEAGESP) foram acomodados em caixas de madeira do tipo M $(29 \mathrm{~kg})$, seguindo o procedimento realizado para distribuição das limas ácidas 'Tahiti' nas redes de comércio no mercado interno. Foram estabelecidos cinco pontos de coleta de frutos ao longo do processo de beneficiamento, que correspondem aos tratamentos estudados: "Campo" coleta diretamente na planta; "Recepção" - coleta na área de recepção da UB; "Repouso" - coleta após a primeira etapa do beneficiamento; "Beneficiamento completo" - coleta após o beneficiamento completo; e "Centro de comercialização" - coleta na recepção do centro de comercialização (Figura 1). Após passarem pelas etapas de beneficiamento e embalagem em caixa do tipo $\mathrm{M}$, os frutos foram transportados de Itajobi-SP até a CEAGESP (São Paulo-SP - distância aproximada de $400 \mathrm{Km}$ ) em caminhão do tipo baú sem refrigeração, pela própria empresa.

As limas ácidas 'Tahiti' de cada um dos tratamentos foram então transportadas para o local de armazenamento experimental em caixas plásticas forradas com espuma (espessura de $1 \mathrm{~cm}$ ), onde foram armazenados em câmaras com temperatura e umidade controladas $\left(22^{\circ} \mathrm{C} \pm 2\right.$ e $70 \pm 5$ de UR), por 20 dias. Foram analisadas, a cada 5 dias, quanto ao teor de acidez titulável (AT), por titulação potenciométrica com hidróxido de sódio $1 \mathrm{~N}$ até $\mathrm{pH} 8,10$ (ponto de 


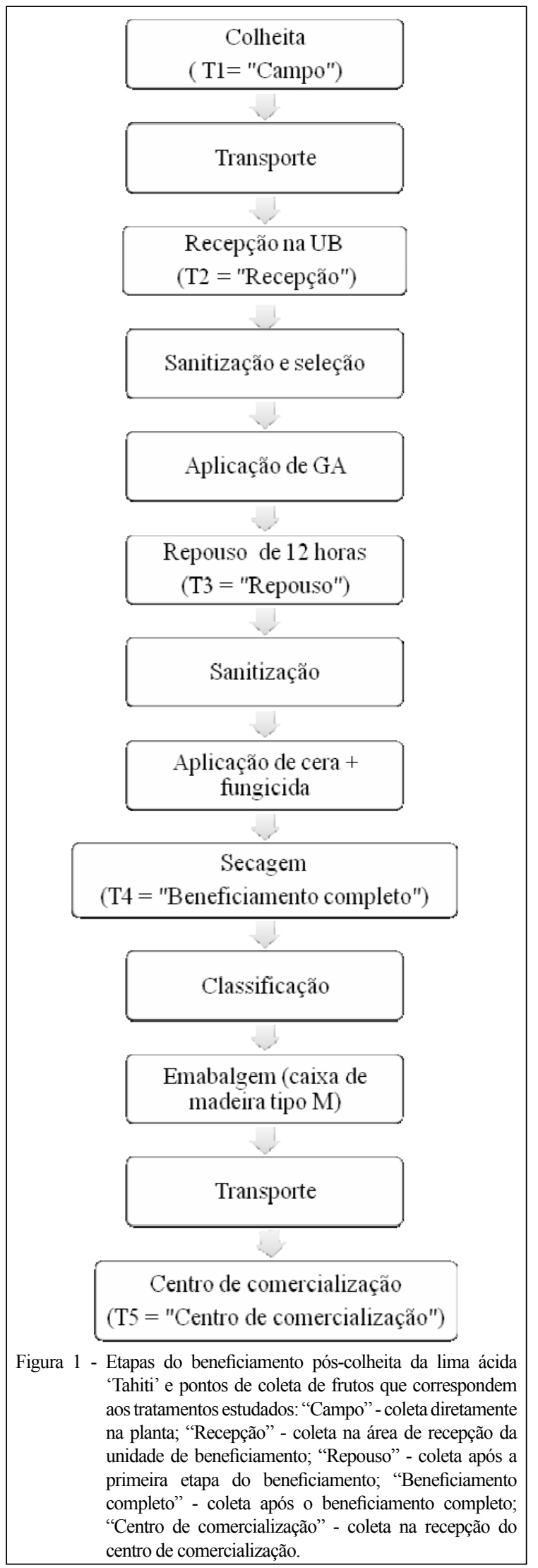

viragem da fenolftaleína) e expresso em porcentagem de ácido cítrico no suco; teor de sólidos solúveis (SS), medido em refratômetro digital, com correção automática de temperatura para $20^{\circ} \mathrm{C}$ e apresentado em ${ }^{\circ}$ Brix; conteúdo de ácido ascórbico com base na redução do indicador 2,6-diclofenol indolfenol-sódio (DCFI) pelo ácido ascórbico e expresso em $\mathrm{mg} \mathrm{g}^{-1}$ de suco; e teor total de clorofila através de solução extratora de acetona $80 \%$ e leitura de absorbância da solução em espectrofotômetro nos comprimentos de onda 646 e $663 \mathrm{~nm}$. Os valores obtidos foram aplicados na seguinte equação:

CT $=7.15$ x (Absorbância a 663nm) + 18.71 x (Absorbância a 646nm). Os resultados foram expressos em miligramas de clorofila por grama de casca. Para coloração da casca, foram realizadas duas medidas por fruto, em lados opostos da região equatorial, com o auxílio do colorímetro Minolta (modelo CR-300) e os resultados foram apresentados através do índice de cor (IC), calculado pela equação:

$\mathrm{IC}=1000 \times \mathrm{a} /(\mathrm{L} \times \mathrm{b})$. Este índice varia entre $-20 \mathrm{a}+20$, sendo que quanto menor for o IC, mais verde é a coloração da casca do fruto (JIMENEZCUESTA et al., 1983).

Um lote de 200 frutos (40 para cada tratamento) foi preservado por 20 dias para a realização de análises quanto à incidência de podridão estilar, oleocelose e perda de massa. Ao final do armazenamento, foi realizada a classificação das limas ácidas 'Tahiti' separando-as em comercializáveis (casca verde, túrgida, sem oleocelose ou podridão estilar) e não comercializáveis (com podridão estilar, oleocelose ou phomopsis). O delineamento experimental foi inteiramente aleatorizado em parcelas subdivididas no tempo, sendo que cada tratamento foi formado por quatro repetições para cada dia de análise. As repetições foram compostas por amostras de 10 frutos.

Os resultados foram submetidos à análise de variância e regressão, sendo esta última utilizada devido ao caráter quantitativo imposto pelo tempo avaliado. Quando significativas, as médias foram comparadas através do teste de Tukey a $5 \%$ de probabilidade. Para os dados de porcentagem (danos mecânicos e distúrbios fisiológicos), foi utilizada a comparação pelo teste de Fisher. As análises foram realizadas no programa SAS (Statistical Analysis System, V. 9.3, Cary, NC, USA).

\section{RESULTADOS E DISCUSSÃO}

A coloração verde da casca da lima ácida 'Tahiti' não foi influenciada pelas etapas de 
beneficiamento pós-colheita, uma vez que, ao longo do período de armazenamento, os valores do índice de cor apresentaram aumento em ordem de grandeza semelhante para todos os tratamentos (Figura 2). A análise do teor total de clorofila da casca, ao final do período de armazenamento, confirmou que não houve influência dos tratamentos na coloração da casca dos frutos (Tabela 1). Portanto, a movimentação, manipulação e impactos sofridos pelo fruto durante o beneficiamento e o transporte não causaram alterações significativas na coloração da casca.
Os frutos coletados após o repouso, no final do beneficiamento e no centro de comercialização, embora tenham recebido aplicação de GA, não apresentaram diferença significativa na coloração nem no teor total de clorofila da casca em relação aos frutos provenientes diretamente do campo e coletados na recepção da UB, que não receberam tal aplicação (Figura 2 e Tabela 1). A manutenção da coloração verde oliva da casca pela aplicação de GA ocorre devido ao efeito retardador da degradação da clorofila, do acúmulo de carotenoides e do amaciamento da

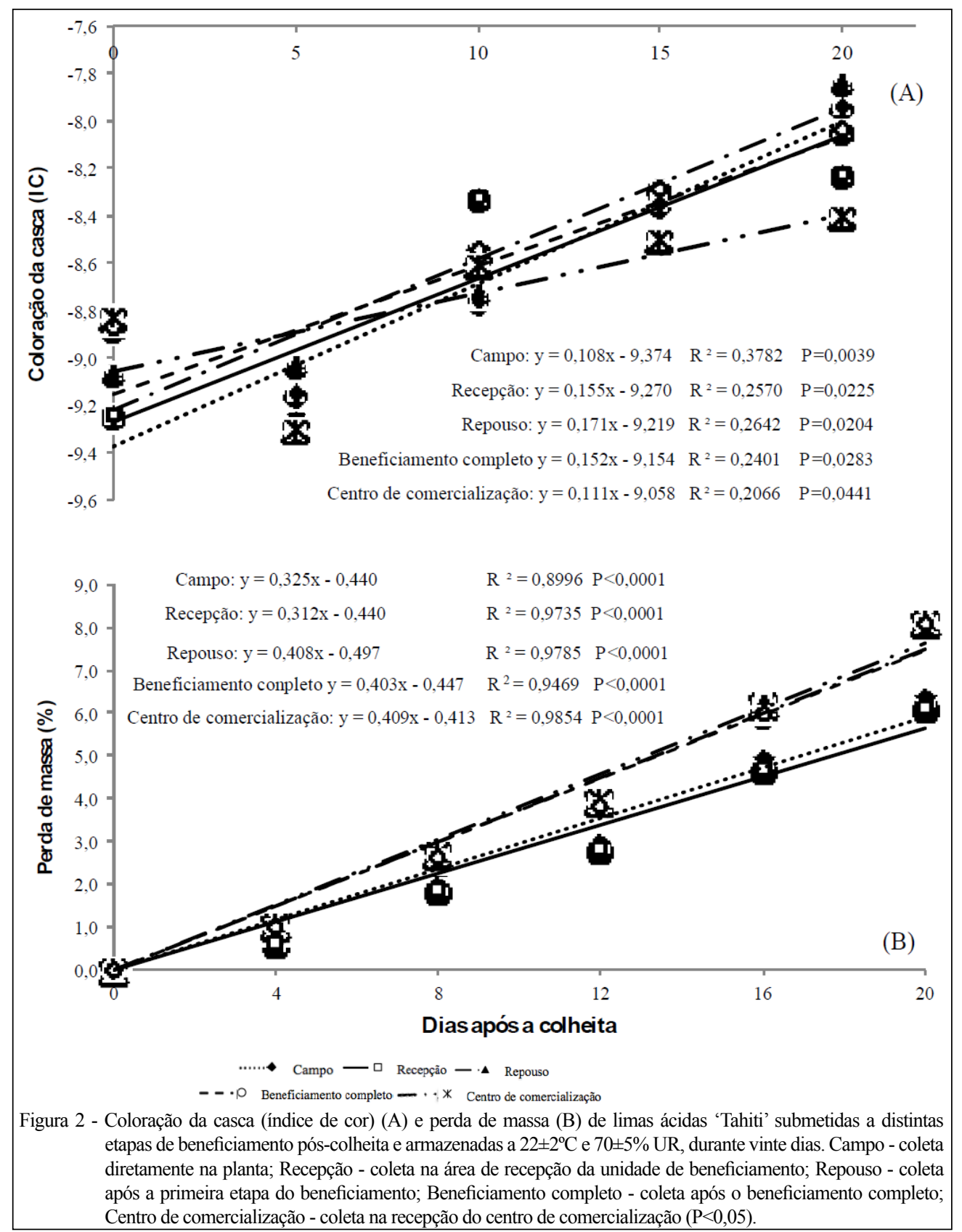

Ciência Rural, v.46, n.1, jan, 2016. 
Tabela 1 - Clorofila, teor de sólidos solúveis (SS), ácido ascórbico (AA), acidez titulável (AT) de limas ácidas 'Tahiti' submetidas a distintas etapas de beneficiamento pós-colheita após vinte dias de armazenamento $\left(22 \pm 2^{\circ} \mathrm{C}\right.$ e $\left.70 \pm 5 \% \mathrm{UR}\right)$.

\begin{tabular}{|c|c|c|c|c|}
\hline Etapas de beneficiamento pós-colheita & Clorofila & SS & AT & AA \\
\hline & $\mathrm{mg} \mathrm{g}^{-1}$ & ${ }^{\circ}$ Brix & \% ácido cítrico & $\mathrm{mg} 100 \mathrm{~g}^{-1}$ \\
\hline Campo & $10,09 \mathrm{a}$ & $8,60 \mathrm{~b}$ & $5,55 \mathrm{a}$ & $33,58 \mathrm{bc}$ \\
\hline Recepção & $10,81 \mathrm{a}$ & $8,97 \mathrm{a}$ & $5,37 \mathrm{a}$ & $37,33 \mathrm{a}$ \\
\hline Repouso & $12,43 \mathrm{a}$ & $8,61 \mathrm{~b}$ & $5,45 \mathrm{a}$ & $36,41 \mathrm{ab}$ \\
\hline Beneficiamento completo & $12,28 \mathrm{a}$ & $8,60 \mathrm{~b}$ & $5,38 \mathrm{a}$ & $32,19 \mathrm{c}$ \\
\hline Centro de comercialização & $12,37 \mathrm{a}$ & $8,52 \mathrm{~b}$ & $5,36 \mathrm{a}$ & $30,79 \mathrm{c}$ \\
\hline $\mathrm{CV}$ & 12,25 & 2,77 & 5,41 & 9,75 \\
\hline
\end{tabular}

Médias com letras distintas nas colunas diferem entre si pelo teste de Tukey $(\mathrm{P}<0,05)$.

*Valores apresentados correspondem à média dos resultados obtidos durante o período de armazenamento.

casca (CHITARRA \& CHITARRRA, 2005). Porém, no presente estudo, observou-se que, quando aplicado em frutos submetidos à manipulação do processo de beneficiamento, a ação do GA pode ter sido superada pelo efeito do etileno, o qual tem um aumento em sua taxa de produção minutos após o sofrimento de um dano físico (CHITARRA \& CHITARRRA, 2005). Em trabalho envolvendo limas ácidas 'Tahiti', a aplicação de GA foi eficiente para a manutenção da coloração verde da casca (BIASI \& ZANETTE, 2000). Por outro lado, trabalhos conduzidos com limas ácidas 'Tahiti' e tangerinas 'Montenegrinas' submetidas a danos físicos apresentaram alteração na coloração da casca mesmo recebendo a aplicação de GA (DURIGAN et al., 2005; MONTERO et al., 2009; BASSAN et al., 2013).

A perda de massa fresca das limas ácidas 'Tahiti' foi maior nos frutos coletados após a etapa do repouso, no final do beneficiamento e no centro de comercialização. Estes tratamentos correspondem aos frutos que sofreram maior manipulação e, consequentemente, submetidos à maior quantidade de danos físicos, quando comparados com os tratamentos que não chegaram a entrar na linha de beneficiamento (Figura 2). Apesar de receberem a aplicação de cera de carnaúba, os frutos coletados no final da linha de beneficiamento e no centro de comercialização apresentaram maior perda de massa fresca, quando comparados aos demais tratamentos que não receberam cera (Figura 2). Tal resultado pode estar relacionado ao fato de que estes frutos foram expostos à maior quantidade de injúrias mecânicas, tais como impacto e compressão, quando comparados aos tratamentos do campo e recepção da $\mathrm{UB}$, em que os frutos passaram apenas pelas etapas da colheita e transporte. Pesquisas conduzidas com lima ácida 'Tahiti' (BASSAN et al., 2013), pêssegos 'Aurora-1' (KASAT et al., 2007) e tangerina 'Rainha'
(MONTERO et al., 2009) também evidenciaram menor conservação da massa fresca dos frutos submetidos a danos físicos.

Os resultados de perda de massa são confirmados pela elevada porcentagem de oleocelose apresentada pelos frutos coletados no final do beneficiamento e no centro de comercialização. As limas ácidas "Tahiti' provenientes das coletas "campo", "recepção" e "repouso" apresentaram de 2,9 a $14,2 \%$ de oleocelose, enquanto que, naquelas coletadas no "beneficiamento completo" e "centro de comercialização", verificou-se, em média, incidência de oleocelose em $44 \%$ dos frutos analisados (Figura 3). Este distúrbio fisiológico ocorre devido ao rompimento das glândulas de óleo da casca das limas ácidas 'Tahiti' devido a fortes pressões e impacto (MONTERO et al., 2012).

Maior porcentagem de frutos em condições de comercialização (túrgido, casca verde, sem podridão e distúrbio fisiológico) foi constatada em tratamentos que não foram submetidos a todas as etapas do beneficiamento pós-colheita (Figura 3). Injúrias mecânicas causadas pelos sistemas de colheita de lima ácida 'Tahiti' também afetaram negativamente a eficiência dos tratamentos póscolheita, utilizados no processo de beneficiamento dessa fruta (BASSAN et al., 2013).

Também foi verificada a incidência da podridão peduncular, causada pelo fungo Phomopis citri. No presente trabalho, os primeiros frutos infectados foram detectados sete dias após o beneficiamento para a coleta após a etapa de repouso. $\mathrm{O}$ fato de as limas ácidas 'Tahiti' coletadas após o período de repouso terem permanecido úmidas (devido ao processo de lavagem) e em caixas plásticas, em condição ambiente de temperatura e umidade, e não terem passado pelo processo de secagem, pode ter propiciado a alta incidência dessa podridão para este tratamento (Figura 3). 


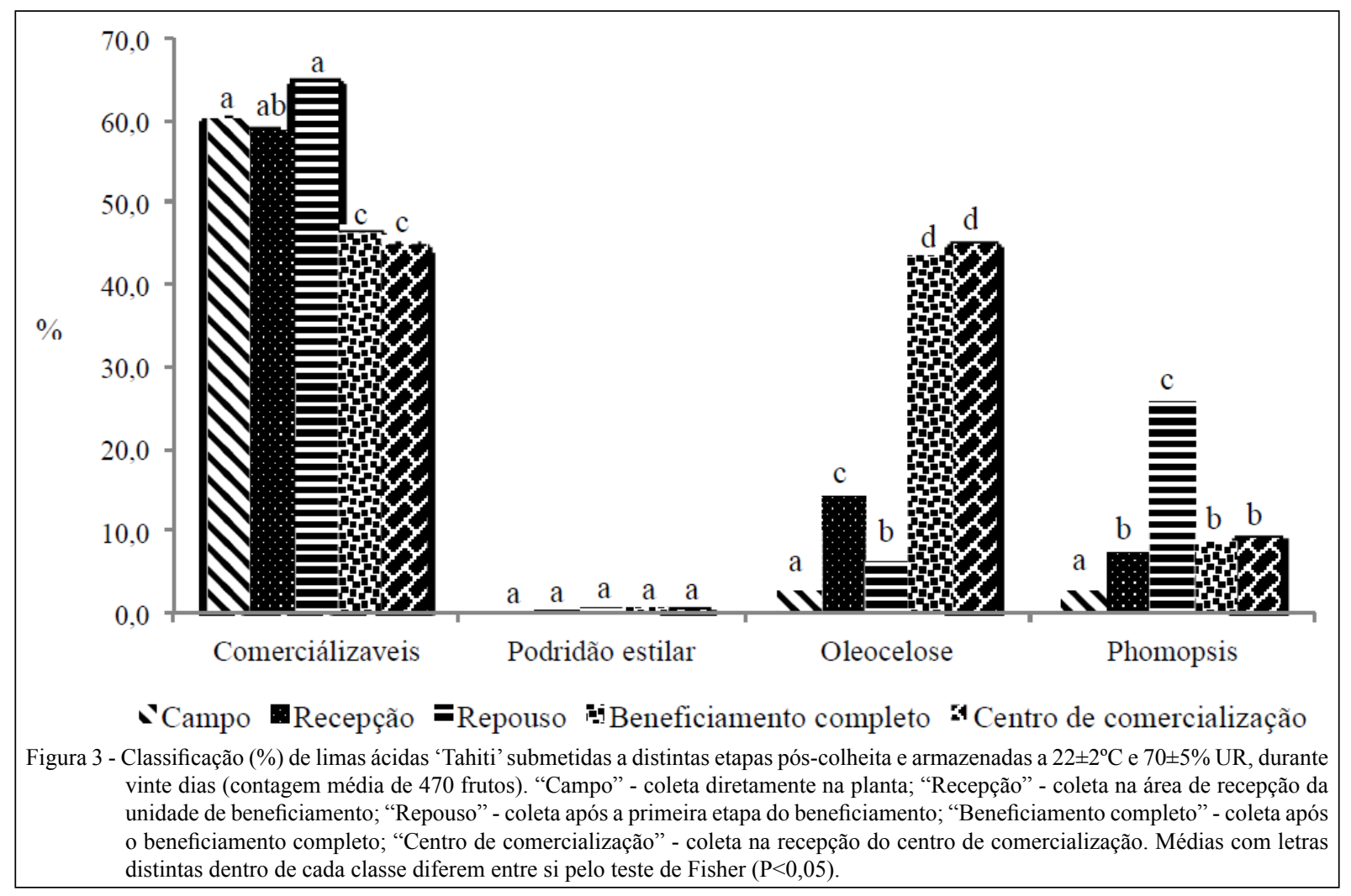

Com base na observação visual da degradação e do escurecimento da polpa nos locais que sofreram o impacto durante as etapas de beneficiamento pós-colheita, constatou-se redução da qualidade interna dos frutos coletados após o repouso, beneficiamento completo e no centro de comercialização. Estudo com maçãs 'Gala' submetidas a impactos também evidenciou modificações significativas na cor da região lesionada (STEFFENS et al., 2008).

Frutos coletados na recepção da UB apresentaram valores superiores de sólidos solúveis em relação àqueles provenientes das demais etapas de beneficiamento pós-colheita (Tabela 1). Contudo, essa variação observada não é relevante do ponto de vista comercial e não pode ser atribuída aos tratamentos estudados. A variável acidez titulável também não sofreu alterações significativas em função das distintas etapas de beneficiamento pós-colheita (Tabela 1). Entretanto, trabalho realizado com lima ácida 'Tahiti' submetida a injúrias mecânicas do tipo corte e impacto, mostrou diminuição no teor de sólidos solúveis dos frutos submetidos aos tratamentos injuriantes, em relação ao controle, e redução nos valores de acidez titulável nos frutos submetidos ao dano por impacto (TAMURA et al., 2010). Em estudo realizado para avaliar a qualidade pós-colheita de abacates 'Fuerte' e
'Hass' beneficiados em packinghouse, os teores médios de sólidos solúveis da cultivar 'Fuerte' também não foram afetados pelas etapas do beneficiamento. Em relação à acidez titulável, houve mudança significativa dessa variável para ambas as cultivares analisadas, em função das diferentes etapas do beneficiamento (FISCHER et al., 2011).

Frutos coletados após o beneficiamento completo e no centro de comercialização apresentaram menor teor de ácido ascórbico, quando comparados aos frutos provenientes dos demais tratamentos (Tabela 1). Injúrias mecânicas podem causar danos aos sistemas protetores antioxidantes associados com o ácido ascórbico, permitindo a depleção oxidativa irreversível do ácido ascórbico a ácido 2,3 diceto L-gulônico (BURTON \& SCHULTE-PASON, 1987). Resultados semelhantes foram obtidos com limas ácidas 'Tahiti' (DURIGAN et al., 2005; TAMURA et al., 2010; BASSAN et al., 2013) e tangerinas 'Montenegrina' e 'Rainha' (MONTERO et al., 2009), submetidas a injúrias mecânicas.

\section{CONCLUSÃO}

A movimentação, manipulação e injúrias mecânicas às quais os frutos de lima ácida 'Tahiti' foram submetidos durante as etapas de

Ciência Rural, v.46, n.1, jan, 2016. 
beneficiamento pós-colheita levaram à redução da eficiência das tecnologias utilizadas durante este processo, prejudicando sua qualidade e conservação.

\section{AGRADECIMENTOS}

Ao apoio financeiro fornecido pela Fundação de Amparo à Pesquisa do Estado de São Paulo (Projeto FAPESP 2010/03835-8). À Itacitrus Agroindustrial e Exportadora S/A, pela colaboração e fornecimento da estrutura para realização deste trabalho e às Doutoras Vanessa Cristina Caron e Patrícia Maria Pinto, pela colaboração na realização das análises.

\section{REFERÊNCIAS}

BASSAN, M.M. et al. The harvesting system affects the quality and conservation of the 'Tahiti' acid lime. Scientia Horticulturae, v.155, p.72-77, 2013. Disponível em: <http://dx.doi.org/10.1016/j. scienta.2013.03.008>. Acesso em: 12 maio 2014. doi: 10.1016/j. scienta.2013.03.008

BIASI, L.A.; ZANETTE, F. GA isolado ou associado com cera na conservação pós-colheita de lima ácida 'Tahiti'. Scientia Agraria, v.1, n.1, p.39-44, 2000

BURTON, C.L.; SCHULTE-PASON, N.L. Carbon dioxide as an indicator of fruit impact damage. HortScience, v.22, p.281-282, 1987.

CHITARRA, M.I.F.; CHITARRA, A.B. Pós-colheita de frutas e hortaliças fisiologia e manejo. Lavras: UFLA, 2005. 785p.

DURIGAN, M.F.B et al. Injúrias mecânicas na qualidade póscolheita de lima ácida 'Tahiti' armazenada sob ambiente. Revista Brasileira de Fruticultura, v.27, p.369-372, 2005. Disponível em: $<$ http://dx.doi.org/10.1590/S0100-29452005000300008>. Acesso em: 15 jun 2012. doi: 10.1590/S0100-29452005000300008.

FISCHER, I.H. et al. Poìs-colheita de abacates 'Fuerte' e 'Hass': características físicas e químicas, danos e controle de doenças.
Semina: Ciências Agraìrias, v.32, p.209-220, 2011. Disponível em: $<\mathrm{http}$ //dx.doi.org/10.5433/1679-0359.2011v32n1p209>. Acesso em: 10 maio 2012. doi: 10.5433/1679-0359.2011v32n1p209.

GAYET, J.P.; SALVO FILHO, A. de. Colheita e beneficiamento. In: MATTOS JUNIOR, D. de et al. Lima ácida 'Tahiti'. Campinas: Instituto Agronômico, 2003. p.147-162.

JIMENEZ-CUESTA, $M$. et al. Teoria $\mathbf{y}$ practica de la desverdización de los cítricos. Madrid: INIA, 1983. 22p. (INIA. Hoja técnica, 46).

KASAT, G.F. et al. Injuìrias mecânicas e seus efeitos em pêssegos 'Aurora-1'. Revista Brasileira de Fruticultura, v.29, p.318322, 2007. Disponível em: <http://dx.doi.org/10.1590/S0100$29452007000200025>$. Acesso em: 15 jul. 2012. doi: 10.1590/ S0100-29452007000200025.

MONTERO, C.R.S. et al. Postharvest mechanical damage affects fruit quality of 'Montenegrina' and 'Rainha' tangerines. Pesquisa Agropecuária Brasileira, v.44, p.1636-1640, 2009. Disponível em: $<$ http://dx.doi.org/10.1590/S0100-204X2009001200011>. Acesso em: 10 maio 2012.doi: 10.1590/S0100-204X2009001200011.

MONTERO, C.R.S. et al. Oleocellosis incidence in citrus fruit in response to mechanical injuries. Scientia Horticulturae, v.134, p.227-231, 2012. Disponível em: <http://dx.doi.org/10.1016/j. scienta.2011.10.026>. Acesso em: 05 jul. 2013. doi: 10.1016/j. scienta.2011.10.026.

STEFFENS, C.A. et al. Respiração, produção de etileno e qualidade de maçãs 'Gala' em função do dano mecânico por impacto e da aplicação de 1- metilciclopropeno. Ciência Rural, v.38, p.18641870, 2008. Disponível em <http://dx.doi.org/10.1590/S010384782008000700010>. Acesso em: 20 maio 2012. doi: 10.1590/ S0103-84782008000700010.

TAMURA, M.S. et al. Avaliação pós-colheita dos parâmetros físico-químicos das limas ácidas 'Tahiti' que sofreram danos mecânicos. Revista Brasileira de Pesquisa em Alimentos, v.1, p.79-82, 2010. 